\title{
Transnational Relationships and Cultural Identity of Older Migrants
}

\author{
Vanessa Burholt ${ }^{1}$, Christine Dobbs ${ }^{1}$, and Christina Victor ${ }^{2}$ \\ ${ }^{1}$ Centre for Innovative Ageing, College of Human and Health Science, Swansea University, Wales, UK \\ ${ }^{2}$ College of Health and Life Sciences, Brunel University, Uxbridge, UK
}

\begin{abstract}
We take a social identity approach to explore the associations between cultural heritage, social class, social-support networks, transnational relationships and cultural identity. Data for 815 older people ( $\geq 55$ years) from six ethnic groups living in England and Wales are used to help understand older migrants' ethnic identity, cultural identity with the family's country of origin, and British identity. Regression models explain a low amount of variance. Different configurations of the independent variables - cultural heritage, social class, social-support networks and transnational relationships (with children, siblings, other relatives) - predicted different forms of cultural identity. Transnational relationships provide migrants with a range of alternative identities into which they self-categorize or contrast to their group identity.
\end{abstract}

Keywords: aging, family interaction, migrant families, multigenerational relations, social identity theory

\section{Introduction}

In this article, we take a social identity approach to identifying factors that are associated with older migrants' cultural identity: their sense of belonging in a rapidly globalizing world. The extent to which migrants feel they belong to the country in which they reside and/or to the country of origin of their family and/or ethnic group is likely to have an impact on social cohesion. This article focuses on an understudied field, that is, older migrants in Europe, providing a deeper insight into the integration of older migrants - a population that is growing currently in many European countries. We draw on a unique dataset in the UK comprising a diverse population (in terms of ethnicity and social class). A social identity approach allows us to test and explore the associations between cultural heritage, social class, social-support network types, transnational family relationships and "cultural identity." Cultural identity is an umbrella term for three identity measures: a migrant's sense of belonging to (1) an ethnic group, (2) the family's country of origin and (3) the country of residence, in this case the UK. We refer to these throughout the article as (1) ethnic identity, (2) cultural identity with the family's country of origin, and (3) British identity. Where the type of identity is nonspecific, we use the term "cultural identity." Our article addresses one main question:

How are cultural heritage, social class, social-support networks, and transnational family relationships associated with cultural identity?

We start by outlining social identity theories that have been used to explain cultural identity. We then move on to discuss the factors that are assumed to influence belonging and raise hypotheses based on the evidence presented.

\section{Social Identity Theory and Cultural Identity}

Social identity theory (Tajfel \& Turner, 1986) and the closely allied self-categorization theory (Turner, Hogg, Oakes, Reicher, $\&$ Wetherell, 1987) have roots in social interactionism in which the self is a product of social interaction (Mead, 1934). Both theories explain self-identity in terms of group processes and intergroup relationships. Broadly speaking, social identity theory concerns the affective-evaluative element of intergroup relationships, while self-categorization theory comprises the cognitive-perceptual component. In this paper both are subsumed within the "social identity approach." This approach suggests that the degree of social identification with a particular group in society is based on perceived shared characteristics, beliefs, and/or behaviors. Groups may be based on nationality, political affiliation, religion, sex, geographical location, social status, and so on, or based on combinations thereof. Social identities "both describe and prescribe one's attributes as a member of that group [...] that is, what one should think and feel and how one should behave" (Hogg, Terry, \& White, 1995, p. 206). Selfcategorization into a group (e.g., based on certain attributes such as economic status, sex, and age) underscores the extent to which one feels one belongs to that group. It provides a sense of self-identity and self-verification (Hogg et al., 1995).

A social identity approach focuses on intergroup relationships. Self-categorization within a particular group entails dif- 
ferentiation from other groups by pronouncing or accentuating positive attributes of the ingroup and negative attributes of the outgroup(s), resulting in self-enhancing outcomes such as improved self-esteem for members of the ingroup (Stets \& Burke, 2000). The strength of comparison with other groups are influenced by subjective belief structures concerning the perceived legitimacy and stability of the status that the group holds (Hogg et al., 1995).

A social identity approach can account for the complexity of multiple, context-specific social identities, because people may have as many distinct self-defined identities as there are groups whose opinions matter to them (James, 1890/1950). Phinney and Ong (2007) noted that "a commitment, or sense of belonging, is perhaps the most important component" of cultural identity (p. 272). Thus, we operationalize cultural identity as the extent to which migrants feel they belong to the country in which they reside (the UK), the country of origin of their family, or ethnic group. In this article, we take a social identity approach to examine the potential for different influences on cultural identity arising from group membership based on cultural heritage, social class, support network, and global citizenship (transnational relationship type) (Roccas \& Brewer, 2002).

\section{Cultural Heritage and Cultural Identity}

Cultural heritage differs from cultural identity inasmuch as the former is "made in the present but has recourse to the past" (Aronsson \& Gradén, 2013, pp. 9-10) and is based on the singularity or plurality of ethnic group membership over time, while the latter is based on an individual's sense of belonging (Phinney \& Ong, 2007). Thus, an individual's cultural heritage is forged within the culture of the family of origin and the trappings that accompany that culture, such as the dress code, food, traditions, and values (UNESCO, 2003). However, cultural heritage is also influenced by the culture and accoutrements of the place or places in which one lives or has lived, so that inheritance of culture from generation to generation can take on new as well as familiar forms. Cultural heritage is to a certain extent governed by one's circumstances and a common cultural heritage would be dependent on shared histories. For example, many Indians living in the UK have never lived in India, but in fact were expelled from Africa (e.g., from Uganda, Kenya and Tanzania) during the Africanization of labor in the 1970s (Burholt, 2004a) and are likely to have a mutual cultural heritage. In this article, we use the terms "ethnic group" and "length of residence in the UK" to indicate a common historical cultural heritage.

Cultural identity is expressed through self-categorization into cultural group(s) because the person feels that they belong (van Oudenhoven, Ward, \& Masgoret, 2006). Thus, cultural identity is a personal experience of representation and "part of an individual's self-concept which derives from knowledge of membership of a social group (or groups) together with the value and emotional significance attached to that membership"
(Tajfel, 1981, p. 255). Some research suggests that long-term exposure to racism (Karlsen \& Nazroo, 2013) or identity denial (whereby individuals from ethnic groups are seen as less prototypically British because of their language, appearance, attitudes or behavior; Cheryan \& Monin, 2005) may decrease a sense of British identity. However, the majority of research suggests that emotional ties to and identification with places and communities strengthen over time (Burholt, Curry, Keating, \& Eales, 2014). Thus, our first hypothesis posits that (H1a) there will be differences between ethnic groups with regard to the time spent in the $U K$ and ( $\mathrm{H} 1 \mathrm{~b})$ longer residence in the $U K$ will be associated with a stronger British identity.

\section{Social Class and Cultural Identity}

Many commentators suggest that Britain is no longer a "deeply class conscious society” (Savage, 2000, p. 40). Nowadays, although class inequalities persist, social class rarely confers membership of a particular group in the UK. Despite a perceived detachment of cultural identity from social class (Bottero, 2004), this may not hold true for all groups in society. Older migrants may identify with a particular social class and be influenced by the perceived or actual power accorded to it. A few studies have found that higher social class is linked to stronger ethnic identity, possibly because better education produces heightened ethnic awareness (Khanna, 2016). For example, Asian and Black Americans (with partners from a different ethnic group) are more likely to label children as Asian or Black, respectively (Qian, 2004; Xie \& Goyette, 1997). Conversely, a majority of theorists suggest that the stigmatization and devaluing of lower status groups may reinforce ethnic solidarity and identity (Khanna, 2016). For example, in the USA many Black youths develop positive ethnic identities rejecting negative and low-status stereotypes (Cross \& FhagenSmith, 2001). For some older migrants in the UK (e.g., older Sylheti men), patterns of settlement, hypercyclical employment, and unemployment may contribute to shared socioeconomic class experience and decreased British identity (Burholt, 2004a). Given the weight of evidence concerning the direction of influence of social class and ethnic identity, we hypothesize that (H2a) migrants with lower socioeconomic status will have a stronger ethnic identity. However, with a focus on British identity, we hypothesize that (H2b) migrants with lower socioeconomic status will have a weaker British identity than those with higher socioeconomic status.

\section{Social Support Networks and Cultural Identity}

Each older migrant is embedded within a social network: a configuration of family, friends and neighbors to whom they have social ties. The social-support network is a vehicle for potential 
support and also may be responsible for determining individual behavior. In this respect, the selection of group membership (a social-support network) is likely to be influenced by the extent to which members of the group reinforce or give credibility to a commitment to a particular social identity that has been developed over time (Hitlin \& Elder, 2007). Research has found that cultural diversity within networks (versus monocultural uniformity) contributes to multicultural identities (Mao \& Shen, 2015). Thus, we would expect older people with diverse social-support networks to express their cross-cultural interconnectedness through the strength of plural cultural identities. While family-focused monocultural networks are likely to have strong ethnic identities, there is no reason to expect them to be any stronger or weaker than for those people with diverse networks. On the other hand, we hypothesize that (H3) older people with diverse networks will have stronger British identities than those with family focused networks.

\section{Transnational Family Relationships and Cultural Identity}

Transnationalism is defined as the process by which migrants forge and sustain multistranded social relations that link their societies of origin and settlement through the creation of crossborder and intercontinental networks (Vertovec, 1999). Transnationalism is facilitated by "space- and time-compressing technology” (Portes, Guarnizo, \& Landolt, 1999, p. 222) within an infrastructure that encompasses new communication technology and relatively easy long-distance cross-border travel. Ten years ago, research with South Asian elders found that different migrant groups in the UK were more or less disposed to maintaining transnational social bonds with relatives through telephone contact, sending remittances, or gifts and visiting (Burholt, 2004b; Burholt \& Wenger, 2004). Transnational contact using information communication technology (ICT) such as email and voice or video calls via the internet (e.g., Skype) was less common at that time. Some authors have suggested that globalization through the use of ICT has generated movement toward a "homogeneous global village" in which national identities are jeopardized (Neyestani \& McInturff, 2006, p. 91). In the present study we expect specific types of transnational family behavior to impact on the formation of national cultural identities. Specifically, we posit that (H4a) transnational relationships typified by frequent visiting and other forms of traditional transnational contact between family members living abroad are associated with a stronger cultural identity with the family's country of origin and a stronger ethnic identity; and that (H4b) transnational relationships characterized by contact through ICT are associated with a weaker cultural identity with the family's country of origin, ethnic identity and British identity.

We would expect to see associations between the types of transnational relationships (based on frequency and type of contact) and cultural identity for specific dyadic relationships (e.g., parent-child, siblings, and relatives). For example, research showed that parent-child relationships are more frequently described in terms of functional exchanges of support. Relationships with siblings are significant throughout life, and most siblings have a commitment to maintaining the relationship. There is also evidence to indicate that sibling relationships may become more affectionate in later life (Wenger \& Burholt, 2001). However, there are differences between cultures in their expectations concerning functional reciprocity (Burholt \& Dobbs, 2010). The extent to which transnational relationship dyads enact or deviate from these affectionate or functional norms may impact older people's sense of ethnic identity. Because there is insufficient evidence on transnational relationships to support hypotheses, in this article we explore the associations between transnational relationship types and cultural identity separately for (1) parent-child, (2) sibling, and (3) other relative dyads.

\section{Methods}

The data used in this article arise from the study "Inter, Intragenerational and Transnational Caring in Minority Communities in England and Wales.” This project examined the prevalence of informal care among six major minority ethnic groups. The study population comprised adults aged $40+$ years from six ethnic groups: Black Caribbean, Black African, Indian, Pakistani, Bangladeshi, and Chinese people living in England and Wales. The target sample size was 1,200 (stratified as 100 persons per ethnic and generational group: 600 aged 40-64 years and 600 aged $65+$ years). A face-to-face survey was conducted with $N=1,206$ people. Indepth qualitative interviews were conducted with $n=60$ participants (five from each of the six ethnic and two generational groups). The study aimed to explore the meanings of care, how responsibilities and obligations associated with "care" are negotiated across and between generations and transnationally. This article is based on a subsample of $n=815$ older people aged 55 years or more. The age threshold of the subsample was based on previous studies of older migrants in the UK, the shorter life expectancy of some of the migrant groups and the relative youth of the immigrant population in the United Kingdom (Burholt 2004a, 2004b).

\section{Procedure}

We identified sampling points for each ethnic group in England and Wales using the Postcode Address File (PAF) that divides the United Kingdom into postcode districts comprising around 30,000 postcodes (Royal Mail, 2009). Information from the UK Census 2001 was used to construct a data file for popula- 
tions of each ethnic group organized at the PAF locality level. The PAF localities were ordered according to the population size of each ethnic group, separately for each ethnic group in England and each ethnic group in Wales (12 lists in total); systematic random sampling was used to select sampling points on each list.

The interview schedule was compiled in English and included items from a project conducted in South Asia and Birmingham (Burholt \& Dobbs, 2014) and from the Survey of Household Carers 2009-2010 (National Health Service Information Centre, 2010). Questions were comparable to the original English items in terms of appropriateness and meaning and considered conceptual matters, cultural relevance, and the subtle connotations of words and phrases (Hunt, 2003). For the majority of survey questions, conceptual and functional equivalence was straightforward: these items were translated directly from English to Punjabi, Gujarati, Hindi, Mandarin Chinese, Bengali, Somali, Yoruba, or Urdu during the course of the interview. This method of translation is standard practice for the research group (e.g., Grant \& Bowling, 2011). Twenty questions were translated into the respective eight languages using front/backtranslation methods (Koller et al., 2007).

Interviews were conducted by a market research group (Ethnic Focus) between October 2011 and April 2012 in the respondent's native language or in English and, wherever possible, in the respondents' own homes. Potential participants approached by Ethnic Focus who did not identify with one of the six ethnic groups were not eligible for inclusion in the study and were not interviewed.

\section{Sample}

Overall, the response rate was 40\% (Black African: $41 \%$; Black Caribbean: 41\%; Indian: 48\%; Pakistani: 44\%; Bangladeshi: $41 \%$; and Chinese: $27 \%$ ). The net final size was $N=1,206$. This article is based on a subsample of older people aged 55 years or more. The subsample comprised $n=815$ people (Black African: $n=143$; Black Caribbean: $n=162$; Indian: $n=141$; Pakistani: $n=141$; Bangladeshi: $n=134$; Chinese: $n=94$ ).

Each participant was asked to provide information on relationships with all living children and siblings, plus other relatives with whom the participant was in contact (in the last year). Rosters were constructed for children, siblings and other relatives. For example, a respondent with two children would have data on the first two lines of the parent-child roster. From the roster datasets of parent-child, sibling and relative dyads $n=$ 1736 transnational family relationships emerged, that is, where the child $(n=317)$, sibling $(n=747)$ or other relative $(n=672)$ lived overseas.

Descriptive statistics of the sample by ethnic group are presented in Table 1. Black Caribbean participants were on average the oldest participants $(M=68$ years $)(F(5,809)=2.27, p$ $<.05)$ and were more likely than other participants to be never married, divorced or separated. In all other ethnic groups, a majority of participants were married, and between one-fourth and one-third were widowed $\left(\chi^{2}=90.98, d f 15, p<.001\right)$. There were no differences between ethnic groups in the sex of the participants, with the male to female ratio roughly 50:50.

\section{Measures}

\section{Outcome Variables: Cultural Identity}

Three variables captured cultural identity through the participants' sense of belonging to (1) an ethnic group (ethnic identity), (2) the family's country of origin (cultural identity with family's country of origin), and (3) the UK (British identity). The strength of belonging to each group was rated on a 5-point scale $(1=$ not at all strong, 5 = very strong $)$.

\section{Social Class}

Socioeconomic status/social class was established using the National Statistics Socioeconomic Classification (NS-SEC), which is the primary social classification in the UK. In 1994, the NSSEC replaced both Social Class based on Occupation (formerly Registrar General's Social Class) and Socioeconomic Groups (Rose \& Pevalin, 2005). Participants were classified using the self-coded method derived from a combination of information on former or current occupation and employment status (including information on size of organization). Data were classified into three occupational classes (1) Managerial and professional occupations, (2) Intermediate occupations, (3) Manual and routine occupations, and a fourth class representing (4) never worked or long-term unemployed (Office for National Statistics, 2005).

\section{Social Support Networks}

We used a classification of social-support network types developed specifically for use with populations from cultures with a familial orientation (Burholt \& Dobbs, 2014). For the purposes of analyses, an older person's network comprised household members, up to five friends (generated in response to the question "Who are your closest friends whom you see most frequently?") and people that were named in responses to questions that asked about functional sources of help (when ill, buying food, cooking, and doing household chores), informational sources of help (financial advice), and emotional support (when unhappy and discussing a personal problem). Networks were characterized by (1) network size, and the proportion (2) male, (3) in each of three age groups ( $<45$ years, 45-65 years and 65+ years), (4) kin, and (5) living in the same household. Using Mplus Version 5, confirmatory latent profile analysis 
Table 1. Demographic characteristics and cultural identity of the sample by ethnic group and for all participants

\begin{tabular}{|c|c|c|c|c|c|c|c|}
\hline & $\begin{array}{l}\text { Black Ca- } \\
\text { ribbean } \\
\text { Mean }(S D) \\
\text { Range } \\
{[N=162]}\end{array}$ & $\begin{array}{l}\text { Black Afri- } \\
\text { can } \\
\text { Mean }(S D) \\
{[N=143]}\end{array}$ & $\begin{array}{l}\text { Indian } \\
\text { Mean (SD) }\end{array}$ & $\begin{array}{l}\text { Pakistani } \\
\text { Mean (SD) }\end{array}$ & $\begin{array}{l}\text { Banglade- } \\
\text { shi } \\
\text { Mean }(S D) \\
{[N=134]}\end{array}$ & $\begin{array}{l}\text { Chinese } \\
\text { Mean }(S D)\end{array}$ & $\begin{array}{l}\text { All } \\
\text { Mean (SD) } \\
{[N=815]}\end{array}$ \\
\hline Age* & $\begin{array}{l}68.0(6.8) \\
55-85\end{array}$ & $\begin{array}{l}66.2(5.5) \\
55-78\end{array}$ & $\begin{array}{l}55.8(6.4) \\
55-92\end{array}$ & $\begin{array}{l}67.1(5.4) \\
55-82\end{array}$ & $\begin{array}{l}66.1(4.5) \\
55-78\end{array}$ & $\begin{array}{l}67.5(6.7) \\
55-89\end{array}$ & $\begin{array}{l}67.0(6.0) \\
55-92\end{array}$ \\
\hline Years living in the UK*** & $\begin{array}{l}51.3(5.3) \\
21-67\end{array}$ & $\begin{array}{l}31.1(12.7) \\
4-72\end{array}$ & $\begin{array}{l}42.1(9.6) \\
7-65\end{array}$ & $\begin{array}{l}39.5(8.5) \\
11-62\end{array}$ & $\begin{array}{l}34.9(6.6) \\
11-49\end{array}$ & $\begin{array}{l}38.5(9.1) \\
13-64\end{array}$ & $\begin{array}{l}40.0(11.1) \\
4-72\end{array}$ \\
\hline \multicolumn{8}{|l|}{ Sex } \\
\hline Male & $50.6 \%$ & $51.7 \%$ & $48.9 \%$ & $46.1 \%$ & $48.5 \%$ & $43.6 \%$ & $48.6 \%$ \\
\hline Female & $49.4 \%$ & $48.3 \%$ & $51.1 \%$ & $53.9 \%$ & $51.5 \%$ & $56.4 \%$ & $51.4 \%$ \\
\hline \multicolumn{8}{|l|}{ Marital Status*** } \\
\hline Never married & $7.4 \%$ & $4.2 \%$ & $2.8 \%$ & $0 \%$ & $0 \%$ & $3.2 \%$ & $3.1 \%$ \\
\hline Married/partnership & $49.4 \%$ & $53.1 \%$ & $64.5 \%$ & $68.8 \%$ & $65.7 \%$ & $64.9 \%$ & $60.5 \%$ \\
\hline Divorced/separated & $27.2 \%$ & $16.8 \%$ & $2.8 \%$ & $6.4 \%$ & $3.7 \%$ & $12.8 \%$ & $12.0 \%$ \\
\hline Widowed & $16.0 \%$ & $25.9 \%$ & $29.8 \%$ & $24.8 \%$ & $30.6 \%$ & $19.1 \%$ & $24.4 \%$ \\
\hline \multicolumn{8}{|l|}{ NS-SEC classification of occupation*** } \\
\hline Managerial and professional & $16.1 \%$ & $14.3 \%$ & $14.3 \%$ & $9.2 \%$ & $9.0 \%$ & $18.1 \%$ & $13.3 \%$ \\
\hline Intermediate & $23.0 \%$ & $7.1 \%$ & $17.9 \%$ & $10.6 \%$ & $12.7 \%$ & $22.3 \%$ & $15.4 \%$ \\
\hline Routine and manual & $41.0 \%$ & $36.4 \%$ & $46.4 \%$ & $33.3 \%$ & $38.1 \%$ & $36.2 \%$ & $38.8 \%$ \\
\hline Never worked and long-term unemployed & $19.9 \%$ & $42.1 \%$ & $21.4 \%$ & $46.8 \%$ & $40.3 \%$ & $23.4 \%$ & $32.5 \%$ \\
\hline \multicolumn{8}{|l|}{ Network type ${ }^{\star \star \star}$} \\
\hline Multigenerational Household: Older Integrated Network & $16.7 \%$ & $16.1 \%$ & $22.7 \%$ & $21.3 \%$ & $17.9 \%$ & $21.3 \%$ & $19.1 \%$ \\
\hline Multigenerational Household: Younger Family Network & $29.6 \%$ & $54.5 \%$ & $46.8 \%$ & $58.2 \%$ & $68.7 \%$ & $36.2 \%$ & $49.1 \%$ \\
\hline Middle-Aged Friends Network & $23.5 \%$ & $12.6 \%$ & $14.2 \%$ & $8.5 \%$ & $6.7 \%$ & $20.2 \%$ & $14.2 \%$ \\
\hline Restricted Nonkin Network & $30.2 \%$ & $16.8 \%$ & $16.3 \%$ & $12.1 \%$ & $6.7 \%$ & $22.3 \%$ & $17.5 \%$ \\
\hline \multicolumn{8}{|l|}{ Cultural identity } \\
\hline Ethnic identity*** & $\begin{array}{l}4.4(1.1) \\
1-5\end{array}$ & $\begin{array}{l}4.4(1.0) \\
1-5\end{array}$ & $\begin{array}{l}4.8(0.6) \\
1-5\end{array}$ & $\begin{array}{l}4.5(0.9) \\
1-5\end{array}$ & $\begin{array}{l}4.5(0.8) \\
2-5\end{array}$ & $\begin{array}{l}4.0(1.1) \\
1-5\end{array}$ & $\begin{array}{l}4.5(0.9) \\
1-4\end{array}$ \\
\hline With family's country of origin $* \star \star *$ & $\begin{array}{l}4.2(1.2) \\
1-5\end{array}$ & $\begin{array}{l}4.3(1.1) \\
1-5\end{array}$ & $\begin{array}{l}4.7(0.7) \\
1-5\end{array}$ & $\begin{array}{l}4.4(0.9) \\
2-5\end{array}$ & $\begin{array}{l}4.5(0.7) \\
3-5\end{array}$ & $\begin{array}{l}4.0(1.0) \\
2-5\end{array}$ & $\begin{array}{l}4.4(1.0) \\
1-5\end{array}$ \\
\hline British identity*** & $\begin{array}{l}3.4(1.5) \\
1-5\end{array}$ & $\begin{array}{l}3.1(1.3) \\
1-5\end{array}$ & $\begin{array}{l}4.4(1.0) \\
1-5\end{array}$ & $\begin{array}{l}3.6(1.1) \\
1-5\end{array}$ & $\begin{array}{l}3.4(1.0) \\
1-5\end{array}$ & $\begin{array}{l}3.4(1.0) \\
2-5\end{array}$ & $\begin{array}{l}3.6(1.3) \\
1-5\end{array}$ \\
\hline
\end{tabular}

Note. ${ }^{*} p=.05, * * p \leq .01, * * * p \leq .001$. Analysis of variance for age, years living in the UK, and cultural identity using posthoc group comparisons Tukey HSD test: numbers that appear in bold italics constitute subsets with the highest values; numbers that appear in italics constitute subsets with the lowest values.

model tested the fit of the 4-class development model (M1) (based on Burholt \& Dobbs, 2014): Mean values for network size were left free to vary, but all other start values were constrained and set at the mean values identified previously. In the second step, the confirmatory model was tested against three exploratory models with three (M2), four (M3) and five profiles (M4). In these models, no start values were stipulated. In the third step, M1 was compared to a 4-profile model (M5). In this model, mean start values were the same as M1 but were free to vary for three of the four profiles and constrained for the Restricted Nonkin Network. Models were compared using Akaike's Information Criterion (AIC $=2 k-2 l(\mathrm{~L})$ : Akaike, 1987) and the sample size adjusted Bayesian Information Criterion $(\mathrm{aBIC}=-2 * \operatorname{logLikelihood}+p[\ln ((n+2) / 24)$ : Sclove, 1987). We assessed the relative adequacy of the fit of the model using the Vuong-Lo-Mendell-Rubin test (Vuong, 1989). Theoretical reasoning was also used to judge the adequacy of the model (Nylund, 2007). A four-class model (M5) was chosen based on model fit, profile characteristics and theoretical reasoning. Each participant was classified based on their most likely latent class membership (Burholt, Dobbs, Victor, Martin, \& Ahmet, 2013). The networks are described as follows:

- Older people with Multigenerational Households: Younger Family Networks live in multigenerational households and have family-focused lifestyles: They are the least likely to participate in social groups or community meetings, and have networks mainly comprising younger kin (less than 45 years of age).

- Older people with Multigenerational Households: Older Integrated Networks comprise around two-thirds kin and one- 
third nonkin, suggesting that relationships are focused both within and outside the household. On average more than two-thirds of network members are over 65 years old.

- Middle-Aged Friends Networks comprise mainly friends aged between 45 and 64 years, indicating a community-facing lifestyle.

- A majority of older people with Restricted Nonkin Networks live alone. These small networks comprise mainly nonkin members (if any, only one or two friends) who tend to be over 65 years old.

\section{Transnational Family Relationships}

Thirteen variables were used to characterize four types of transnational family relationships (Burholt, 2004b; Burholt \& Wenger, 2004). These captured, for each relative living abroad, the method of communication (letters, telephone, Skype, email, visits to and from relatives), the frequency of contact using any form of communication, alongside the provision of support through the transfer of material resources (sending and receiving regular remittances, sending and receiving irregular or oneoff gifts of money, and sending and receiving other gifts). Four exploratory latent profile models were run with three, four, five, and six profiles. In these models, no start values were stipulated. The 4-class model provided a good fit to the data (although slightly inferior to the 5-class model), and provided a clearer distinction between the types of transnational relationships between family members. Each participant-relative dyad was classified based on their most likely latent class membership (Burholt, Dobbs, \& Victor, 2015). The transnational relationships are described as follows:

- Infrequent Digital Communicator. People with these types of transnational relationships are the highest users of digital communication. Simultaneously, they are the least likely to make telephone calls. Contact is monthly or less frequently and relationships are typified by a low level of visiting. Relationships are also characterized by remittances sent overseas.

- Infrequent Telephone Communicator. The main form of contact for these transnational relationships is by phone once a month or less frequently. Other forms of contact/exchange are relatively rare.

- Highly Connected Regular Benefactor. The main form of contact is through telephone calls, but there is also a high use of email and Skype. Relatives tend to be in contact daily or at least weekly. People with these relationships pay visits overseas and receive visits from relatives to the UK. Remittances and one-off gifts of money are sent overseas from the UK, but people with these relationships rarely receive these types of monetary gifts from the relative abroad.

- Occasional Bilateral-Bounteous-Visitors. This type of transnational relationships is typified by telephone calls and contact at least monthly. People with these relationships pay visits overseas and receive visits from relatives to the UK. Relationships are characterized by the highest levels of bilateral exchange (that is, giving and receiving) of monetary and other forms of gifts when compared to the others.

For each dyadic relationship (i.e., with children, siblings or other relatives) a count of each transnational relationship type was created for each participant. Thus, twelve variables were created (e.g., number of Infrequent Digital Communicator relationships with children; number of Infrequent Digital Communicator relationships with siblings; number of Infrequent Digital Communicator relationships with other relatives).

\section{Data Analyses}

The Statistical Package for the Social Sciences (SPSS) Version 22 was used to analyze data. We compared cultural identity using Wilcoxon signed rank test to contrast participants' ethnic identity, cultural identity with the families' country of origin and British identity. For each form of cultural identity, three multiple regression models were run to determine the relative contribution of the independent variables (nine regression models in total). Each model included sex, socioeconomic class, number of years living in the UK, ethnic group, network type, and a count of transnational relationships types. The latter varied in each of the three models because we wanted to explore the associations for parent-child, sibling, and relative dyads separately. The inclusion of all counts of transnational relationship dyads in one model would identify the strongest predictive relationship with cultural identity, but would not necessarily identify all significant associations. Model 1 included the count of each type of transnational relationship for relative dyads, Model 2 included the count of each type of transnational relationship for parent-child dyads only, and Model 3 included the count of each type of transnational relationships for sibling dyads only. A variance inflation factor (VIF) was calculated for each predictor in the models, with values greater than 10 indicating high levels of multicollinearity (Hair, Anderson, Tatham, \& Black, 1995).

\section{Results}

Regarding our operationalization of cultural heritage, on average, Black Caribbean participants had lived in the UK for the greatest number of years $(M=51.3$ years) and Black African participants the fewest years $(M=31.1$ years $)(F(5,809)=91.7$, $p<.001)$ supporting our hypothesis (H1a) that there would be differences between ethnic groups with regard to the time spent in the UK.

A Kruskal-Wallis test showed significant differences in socioeconomic status between ethnic groups $(H(5)=46.22, p<$ .001) with Pakistani participants ranked highest (correspond- 
Table 2. Regression results predicting cultural identity through ethnic identity, cultural identity with family's country of origin and British identity

\begin{tabular}{lc}
\hline Strength of belonging to: & Ethnic group \\
of origin
\end{tabular}

\begin{tabular}{|c|c|c|c|c|c|c|}
\hline & $b$ & $S E$ & $b$ & $S E$ & $b$ & $S E$ \\
\hline \multicolumn{7}{|l|}{ Model 1} \\
\hline Sex & $0.19 * *$ & 0.07 & $0.15^{\star}$ & 0.07 & 0.06 & 0.09 \\
\hline Socioeconomic status & -0.04 & 0.03 & -0.05 & 0.04 & $-0.19 * \star \star$ & 0.04 \\
\hline \# years living in the UK & 0.00 & 0.00 & -0.00 & 0.00 & $0.02 * \star$ & 0.01 \\
\hline \multicolumn{7}{|l|}{ Ethnicity } \\
\hline Black Caribbean & -0.01 & 0.13 & -0.17 & 0.13 & $-0.34^{\star}$ & 0.16 \\
\hline Black African & -0.02 & 0.11 & -0.13 & 0.12 & -0.19 & 0.15 \\
\hline Indian & $0.36 * *$ & 0.12 & $0.24 *$ & 0.12 & $0.83 * * *$ & 0.15 \\
\hline Pakistani & 0.01 & 0.11 & -0.08 & 0.11 & 0.16 & 0.15 \\
\hline Chinese & $-0.47 * * *$ & 0.13 & $-0.50 * * \star$ & 0.13 & -0.10 & 0.16 \\
\hline \multicolumn{7}{|l|}{ Network type } \\
\hline Middle-Aged Friends & $-0.38 * * \star$ & 0.11 & $-0.29 *$ & 0.12 & -0.22 & 0.15 \\
\hline Restricted Nonkin & -0.16 & 0.11 & -0.08 & 0.11 & -0.04 & 0.14 \\
\hline Multigenerational: Younger Family & -0.05 & 0.09 & -0.04 & 0.09 & -0.18 & 0.11 \\
\hline \multicolumn{7}{|l|}{ \# Transnational Relationship: Relatives } \\
\hline Infrequent Digital Communicators & $-0.12^{\star}$ & 0.06 & -0.10 & 0.06 & -0.08 & 0.07 \\
\hline Infrequent Telephone Communicators & 0.00 & 0.02 & -0.01 & 0.02 & -0.01 & 0.02 \\
\hline Highly Connected Regular Benefactors & 0.06 & 0.03 & $0.07 *$ & 0.03 & 0.08 & 0.04 \\
\hline Occasional Bilateral Bounteous Visitors & 0.08 & 0.06 & 0.08 & 0.06 & 0.01 & 0.08 \\
\hline $\operatorname{Adj} R^{2}$ & \multicolumn{2}{|c|}{$.08 * * *$} & \multicolumn{2}{|c|}{$.06 * * *$} & \multicolumn{2}{|c|}{$.14^{* * *}$} \\
\hline
\end{tabular}

西

Model 2

Sex

Socioeconomic status

$0.18 * * \quad 0.07$

$0.15 *$

0.07

$0.06 \quad 0.09$

\# years living in the UK

$-0.03$

0.03

$-0.04$

$-0.18 * * *$

0.04

thnicity

Black Caribbean

$-0.00$

$-0.00$

0.00

$0.01 * *$

0.01

Black African

$-0.05$

0.13

$-0.21$

0.13

$-0.37 *$

0.16

Indian

$-0.03$

0.11

$-0.14$

0.12

$-0.19$

0.15

Pakistani

Chinese

$0.36 * *$

$0.25 *$

$0.86 * * *$

0.15

etwork type

Middle-Aged Friends

Restricted Nonkin

$0.02 \quad 0.11$

$-0.07$

0.18

0.14

$-0.50 * * *$

0.13

$-0.51 * * *$

0.11

$-0.10$

0.16

Multigenerational: Younger Family

$-0.38 * * *$

$-0.16 \quad 0.11$

$-0.29 *$

0.12

$-0.23$

0.15

$\begin{array}{lll}-0.16 & 0.11 & -0.08\end{array}$

$-0.05$

0.14

$-0.05$

0.09

$-0.04$

0.09

$-0.19$

0.11

\# Transnational Relationships: Children

Infrequent Digital Communicators

Infrequent Telephone Communicators

$\begin{array}{rrrrrr}0.24 & 0.20 & 0.32 & 0.21 & 0.56^{*} & 0.26 \\ -0.06 & 0.05 & -0.08 & 0.05 & -0.06 & 0.06 \\ 0.08 & 0.07 & 0.11 & 0.07 & 0.08 & 0.09 \\ 0.12 & 0.28 & 0.12 & 0.29 & 0.21 & 0.36\end{array}$

Occasional Bilateral Bounteous Visitors

0.12

$.08 * * *$

$\operatorname{Adj} R^{2}$

Sex

$0.18 * *$

0.07

$0.14 *$

0.07

0.06

0.09

Socioeconomic status

$-0.05$

$-0.05$

0.04

$-0.19 * * *$

0.05

\# years living in the UK

0.00

0.00

$-0.00$

0.00

$0.01 * * *$

0.01 
Table 2. Regression results predicting cultural identity through ethnic identity, cultural identity with family's country of origin and British identity (continued)

\begin{tabular}{|c|c|c|c|c|c|c|}
\hline \multirow[t]{2}{*}{ Strength of belonging to: } & \multicolumn{2}{|c|}{ Ethnic group } & \multicolumn{2}{|c|}{$\begin{array}{c}\text { Family's country } \\
\text { of origin }\end{array}$} & \multicolumn{2}{|c|}{ UK } \\
\hline & $b$ & $S E$ & $b$ & $S E$ & $b$ & $S E$ \\
\hline \multicolumn{7}{|l|}{ Ethnicity } \\
\hline Black Caribbean & -0.01 & 0.13 & -0.16 & 0.13 & $-0.35^{\star}$ & 0.17 \\
\hline Black African & -0.02 & 0.11 & -0.14 & 0.12 & -0.20 & 0.15 \\
\hline Indian & $0.34 * * *$ & 0.12 & $0.28 *$ & 0.12 & $0.85 * * *$ & 0.15 \\
\hline Pakistani & 0.02 & 0.11 & -0.07 & 0.12 & 0.17 & 0.15 \\
\hline Chinese & $-0.46 * \star \star$ & 0.13 & $-0.48^{\star \star \star}$ & 0.13 & -0.10 & 0.17 \\
\hline \multicolumn{7}{|l|}{ Network type } \\
\hline Middle-Aged Friends & $-0.37 * \star \star$ & 0.11 & $-0.28 *$ & 0.12 & -0.21 & 0.15 \\
\hline Restricted Nonkin & -0.17 & 0.11 & -0.10 & 0.11 & -0.05 & 0.14 \\
\hline Multigenerational: Younger Family & -0.05 & 0.09 & -0.04 & 0.09 & -0.18 & 0.11 \\
\hline \multicolumn{7}{|l|}{ \# Transnational Relationships: Siblings } \\
\hline Infrequent Digital Communicators & -0.10 & 0.09 & -0.08 & 0.09 & -0.08 & 0.12 \\
\hline Infrequent Telephone Communicators & 0.04 & 0.03 & 0.02 & 0.03 & 0.01 & 0.04 \\
\hline Highly Connected Regular Benefactors & $0.20 *$ & 0.09 & 0.17 & 0.10 & 0.13 & 0.12 \\
\hline Occasional Bilateral Bounteous Visitors & 0.04 & 0.20 & 0.12 & 0.10 & -0.01 & 0.13 \\
\hline Adj $R^{2}$ & \multicolumn{2}{|c|}{$.08 * * *$} & \multicolumn{2}{|c|}{$.06 * * *$} & \multicolumn{2}{|c|}{$.13^{* * *}$} \\
\hline
\end{tabular}

Note: Models and coefficients not marked with asterisks were not significant. Reference groups for categorical variables: ethnicity: Bangladeshi; support networks: multigenerational: older integrated. ${ }^{\star} p<.05,{ }^{\star \star} p=.01,{ }^{\star \star \star} p=.001$.

ing to low occupational class) and Black Caribbeans the lowest (corresponding to high occupational class): Black Caribbean $=$ 343.1, Chinese $=348.2$, Indian $=365.1$, Black African $=448.4$, Bangladeshi $=448.8$, and Pakistani $=471.2$ (mean ranks). Chisquare tests $\left(\chi^{2}=59.6, d f 15, p<.001\right)$ demonstrated that a greater proportion of Pakistani participants were long-term unemployed or never worked (46.8\%), while Indian (21.4\%) and Black Caribbean (19.9\%) participants experienced the lowest levels of unemployment. Differences were also observed for Class 2 (intermediate) occupations; in particular a large proportion of Black Caribbeans were classified in this class (23\%), while very few Black Africans were employed in these types of roles $(7 \%)$.

We evaluated whether there were significant differences in the strength of the various forms of cultural identity within the full sample. The test results indicated that there were no significant differences between cultural identity with the family's country of origin and ethnic identity $(z=-0.47, p<.64)$, but there were significant differences between ethnic identity and British identity $(z=-15.59, p=.001)$, and significant differences between cultural identity with the family's country of origin and British identity $(z=-15.31, p=.001)$. Mean rank scores indicated that the weakest form of cultural identity was British identity. Pearson product-moment coefficients indicated significant intercorrelations between all cultural identity variables: ethnic identity was significantly associated with cultural identity with family's country of origin $(r=0.69, p<.001)$ and British identity $(r=0.33, p<.001)$; and British identity was significantly associated with cultural identity with family's country of origin $(r=0.37, p<.001)$.

Cultural identity (ethnic identity, cultural identity with the family's country of origin, and British identity) differed by ethnic group. Comparing the strength of ethnic identity by ethnic group, Indians reported the strongest identity, and Chinese participants the weakest $(F(5,809)=10.82 p=.001)$. Comparing cultural identity with family's country of origin by ethnic group, Indians and Bangladeshis demonstrated the strongest identity and Chinese and Black Caribbeans the weakest $(F(5,809)=$ 9.17, $p=.001$ ). Finally, British identity (by ethnic group) was strongest for Indians and weakest for all other ethnic groups with the exception of Pakistani participants $(F(5,808)=20.29$, $p=.001)$. Overall, Indians demonstrated a stronger cultural identity across all three areas (ethnic identity, cultural identity with family's country of origin, and British identity) than other ethnic groups.

There were significant differences in the distribution of network types by ethnic group $\left(\chi^{2}=76.59, d f 15, p=.001\right)$. Of particular note were the marked difference in the distribution of network types for Black Caribbeans and Chinese elders. Both had relatively greater proportions of Restricted Nonkin Networks (30\% and 20\% respectively) and Middle-Aged Friends Networks (24\% and 20\% respectively) with fewer Multigenerational Households: Younger Family Networks (30\% and $36 \%$ respectively) than the other ethnic groups. On the 
other hand, Bangladeshi participants had very few Middle-Aged Friends Networks (7\%) and a larger proportion of Multigenerational Households: Younger Family Networks (69\%) than older people in other ethnic groups.

Transnational relationships were predominantly characterized as Infrequent Telephone Communicator in each ethnic group and accounted for $73 \%$ of all relationships. However, differences in distribution of transnational family relationship types were observed between ethnic groups. Specifically, Indian and Pakistani relationships were more frequently classified as Highly Connected Regular Benefactor $(27 \%$ and $22 \%$ respectively), while this type of relationship was infrequent for Chinese participants (8\%). Black Caribbeans had a greater proportion of transnational relationships defined as Infrequent Digital Communicator (13\%) than other ethnic groups, with this type of relationship particularly rare for Pakistani participants (1\%). Transnational family relationships defined as Occasional Bilateral-Bounteous-Visitors were more common for Pakistanis and Bangladeshis (10\% and $12 \%$ respectively) and least common for Black Caribbean and Black African participants ( $1 \%$ of each group) $\left(\chi^{2}=165.35\right.$, df 15, $\left.p=.001\right)$.

\section{Regression Analysis}

Adjusted $R^{2}$ values were small indicating that the models only explained a small amount of variance. However, each model had a significantly better fit to the data than the intercept only model and contained statistically significant predictors from which we draw important conclusions about cultural identities (Table 2). The VIF value for all predictors in each model was $<3$, indicating that there was not a high degree of multicollinearity (Hair et al., 1995).

Sociodemographic variables and ethnicity were associated with cultural identity across all nine models. A stronger ethnic identity and cultural identity with the family's country of origin were predicted by being male and Indian, while a weaker ethnic identity and cultural identity with the family's country of origin were predicted by being Chinese. A stronger British identity was predicted by higher socioeconomic status and a greater number of years living in the country and being Indian. A weaker British identity was related to the Black Caribbean ethnic group. The results were consistent with $\mathrm{H} 1 \mathrm{~b}$, whereby longer residence in the UK was associated with a stronger British identity; and $\mathrm{H} 2 \mathrm{~b}$ inasmuch as migrants with lower socioeconomic status had a weaker British identity than those with higher socioeconomic status. However, $\mathrm{H} 2 \mathrm{a}$ was not supported, and we failed to reject the null hypothesis, that is, there is no association between social class and ethnic identity.

Considering the influence of the role of support networks in cultural identity, having a Middle-aged Friends Network was associated with a weaker ethnic identity (Models 1-3) and cultural identity with the family's country of origin (Mod- els 1-3), but network type was not associated with British identity. This was inconsistent with hypothesis $\mathrm{H} 3$ that stated that older people with diverse networks would have a stronger British identity than those with family focused networks.

The effect of transnational family relationships differed between models and for each type of cultural identity. First, Highly Connected Regular Benefactor transnational relationships were typified by frequent visits and traditional forms of contact with relatives abroad. There was a positive association between the number of Highly Connected Regular Benefactor relationships that older participants had with siblings and ethnic identity (Model 3). Every additional Highly Connected Regular Benefactor transnational relationship with a sibling (e.g., two transnational Highly Connected Regular Benefactor sibling relationships instead of one) increased the ethnic identity score by 0.28 . Similarly, there was a positive relationship between the number of Highly Connected Regular Benefactor relationships with other relatives and cultural identity with the family's country of origin (Model 1). Every additional Highly Connected Regular Benefactor relationship with other relatives abroad strengthened cultural identity with the family's country of origin by 0.29 . The results supported hypothesis $\mathrm{H} 4 \mathrm{a}$, demonstrating that transnational relationships that are typified by frequent visiting and other forms of traditional transnational contact were associated with a stronger ethnic identity (although this was true only for relationships with siblings), and a stronger cultural identity with the family's country of origin (although this was true only for relationships with other relatives).

Second, Infrequent Digital Communicator transnational relationships were characterized by contact through network digital communication such as email and Skype. The analysis showed that a greater number of Infrequent Digital Communicator relationships with other relatives was associated with a weaker ethnic identity (Model 1). Every additional Infrequent Digital Communicator transnational relationship with other relatives decreased the strength of ethnic identity by 0.12 . On the other hand, the positive association between the number of Infrequent Digital Communicator relationships between older adults and children overseas and British identity suggested that these types of relationships may bolster the sense of belonging to the place of residence (Model 2). Every additional Infrequent Digital Communicator with a child overseas increased the strength of British identity by 0.56. The results partially supported hypothesis $\mathrm{H} 4 \mathrm{~b}$ and demonstrated that transnational relationships with other relatives (but not children or siblings) characterized by contact through ICT were associated with a weaker sense of ethnic identity. However, the results did not demonstrate a negative association between these types of relationship and cultural identity with the family's country of origin or British identity. With regard to the latter, the converse was true and Infrequent Digital Communicator transnational relationships with children increased the strength of British identity. 


\section{Discussion}

Across all migrant groups, length of residence in the UK was associated with a stronger British identity. However, after controlling for length of residence our analyses demonstrated that other factors also played a part in determining the strength of belonging. We found that older Indians had the strongest sense of belonging across all cultural identities which may be explained by considering their cultural heritage and migration patterns. Many Indian Gujaratis and Punjabis came to live in the UK from East Africa in the 1970s during the Africanization of labor. Some Indians arrived in Britain in family units of three generations with substantial capital, a good command of the English language, and familiarity with urban institutions and bureaucratic processes in the UK (Burholt, 2004a). These characteristics may have led to a stronger British identity than in other migrants groups. However, we also found that older Indians also held the strongest sense of ethnic identity and cultural identity with the family's country of origin. Older Indian migrants demonstrate cultural identity complexity (multiple, nonconvergent, in-group membership (Roccas \& Brewer, 2002)): They are culturally conservative, and seek to retain norms and values through the reconstruction of a separate Indian identity in Britain (Burholt \& Dobbs, 2010), simultaneously demonstrating a strong sense of British identity.

Chinese elders had the weakest ethnic identity and the weakest cultural identity with the family's country of origin. These associations may also be explained by migration patterns. In the 1950s migrants from Hong Kong expanded the restaurant trade in the UK and Chinese restaurants became significant features of small and large settlements (Christiansen, 2013). In the 1960s and 1970s, a further wave of Chinese economic migrants came from other former British colonies, Malaysia, and Singapore. Because of the wide range of migration histories, the UK Chinese population does not form a cohesive integrated community, but is a complex mix with ethnic, class and professional differences (SiewPeng, 2001). In this respect, it may be difficult for Chinese elders to develop a strong ethnic identity. Simultaneously, rapid transformations in the family's countries of origin may have weakened a sense of identity with the homeland (Johnson, 2007).

The weaker sense of British identity expressed by older Black Caribbeans is likely to have a different origin to that expressed by Chinese elders. Other studies have shown that Black Caribbean people perceive greater levels of discrimination than other ethnic groups in the UK and have reported the most job denial and the most unfair treatment at work (Bhui, Stansfeld, McKenzie, Karlsen, Nazroo, \& Weich, 2005).

Our analysis found that lower socioeconomic status weakens British identity but does not strengthen other forms of cultural identity. In terms of a social identity approach, identification with a particular social class does not appear to increase intragroup solidarity for older migrants, but may have an impact on intergroup conflict operationalized through a weaker sense of British identity.

While exclusion from employment opportunities in Britain may have served to weaken British identity, inclusion into British society may have the opposite effect. Examining the role of support networks on cultural identity, we found that membership with a network characterized by Middle-Aged Friends was associated with a weaker ethnic identity and weaker cultural identity with the family's country of origin. Middle-Aged Friends networks have a community facing lifestyle as indicated by the proportion of friends in the network and the level of participation in religious and community organizations. While family networks are likely to comprise primarily a single ethnic group, networks comprising friends may be more ethnically diverse, possibly influencing participants' sense of cultural identity (see also Mao \& Shen, 2015).

In addition to social-support networks impacting on the sense of belonging, two types of transnational family relationships were predictors of cultural identity: Infrequent Digital Communicators and Highly Connected Regular Benefactors. The impact on cultural identity depended on whoever the transnational relationship was with (i.e., child, sibling, or other relative). We expected the use of ICT to contribute to a supranational identity and to be associated with weaker cultural identities. While we found that Infrequent Digital Communicator transnational relationships with relatives were associated with a weaker ethnic identity, the same type of relationship with children was associated with a stronger British identity. These findings suggest that, when children have moved away from the UK (e.g., to other European countries and North America), differences between cultures are highlighted. While both parent and child generations share ethnic similarities, the differences between them are emphasized through behaviors, values and attitudes associated with local cultures (see also Burholt \& Victor, 2014). A parent may contrast their own Britishness with a child's American or European identity, thereby strengthening their own sense of British identity.

Whereas Infrequent Digital Communicator transnational relationships may highlight differences between family members, Highly Connected Regular Benefactor transnational relationships (with siblings) were associated with stronger ethnic identity and (with relatives) a stronger cultural identity with the family's country of origin. These transnational relationships are differentiated from others by the regularity of contact (daily or at least weekly), visiting relatives overseas, sending remittances and gifts of money. The impact of these types of relationships on the communities in the countries of origin is significant. For example, Indian and Bangladeshi migrants from rural villages and small towns contribute toward civic amenities, landscaping and the building of temples or other places of worship (Burholt et al., 2003). Given the high levels of investment, it is not surprising that people with these types of transnational relationships identify strongly with their country of origin.

The sustained level of involvement with siblings through 
Highly Connected Regular Benefactor relationships in the communities of origin also contributes to a heightened sense of ethnic identity. There is relatively little research on sibling relationships of older people (Silverstein \& Giarrusso, 2010). Siblings share a long history of intimate family experiences and, in the last years of life, are among those very few who have memories of one's own parents and childhood (White, 2001). In this respect, transnational sibling relationships may have a particular role in reinforcing ethnic identity through reminiscence about one's cultural and familial heritage.

\section{Limitations}

There are limitations to the research reported here. First, gaining access to participants from Black and Minority Ethnic groups is challenging. We achieved our target sample for five out of our six groups, but were unable to recruit sufficient Chinese participants, only achieving $75 \%$ of our target. In addition, our overall response rate was $40 \%$. Focusing on five ethnic groups (excluding the Chinese), the response rate increases to $43 \%$, which is broadly in line with "nongovernment" sponsored surveys.

Second, the research highlights the need for caution in reporting generalizations based on an amalgamation of ethnicities, cultures and personal histories. The results draw attention to the possibility of heterogeneous ethnic identities for Chinese elders in the UK (e.g., Hong Kong Chinese, Malaysian Chinese, and Singaporean Chinese). Elsewhere we have shown that important differences exist between "South Asians" (Burholt, 2004b), and subsequently research has moved toward demarcation between migrant groups. Older Chinese migrants should be accorded the same consideration as members of the same broad ethnic classification may have different ethnic identities (see also Fouad \& Brown, 2000).

Third, our analyses are limited because of (1) the cross-sectional nature of data and (2) the low variance that the models accounted for. Longitudinal studies with ethnic groups in the UK (which presently do not exist) could provide opportunities to test causal pathways explaining variance. However in order to better understand cultural identity, the theorizing behind the relationship between predictors and the dependent variables was explicit. The unexplained variance is not an indicator of the quality or explanatory power of the social identity approach to studying cultural identity. However, it may be an indication that such models would benefit from refining. We speculate that the explanatory power may be rationalized to a large degree by the complexities of operationalizing cultural heritage. Cultural heritage is not yet crystallized into a coherent theory, and it is likely that individual experiences (e.g., migration history and settlement patterns) were insufficiently captured by ethnic group and length of residence in the UK. Moreover, our models did not include personality characteristics (Padilla \& Perez, 1993) which may influence individuals to associate with, or reject (more or less strongly) different forms of cultural identity. However, understanding the link be- tween individual characteristics, group membership (social class, social-support networks), transnational family behavior and cultural identity offers the advantage of a "generalizable framework" and may inform future investigations.

\section{Implications}

Overall, our analysis shows that migrants have complex multiple cultural identities based on cultural heritage, social class, socialsupport networks, and transnational relationships. Our novel focus on transnational family relationships demonstrated that it is not just contact with relatives abroad that is important to cultural identity, but the type of relationship and who the relationship is with (i.e., all relatives, children, or siblings). We demonstrated that transnational family relationships provide migrants with a range of alternatives identities into which they can self-categorize and identify with, or with which they can contrast to their group identity. This is important because to date research on transnational family ties has not examined the complexity underpinning these relationships.

Transnational relationships with relatives can reinforce a sense of belonging to a country of origin through high levels of investment in communities overseas. They can strengthen a sense of ethnic identity through emphasizing similarities with siblings, yet strengthen British identity through accentuating differences between the Britishness of parents when contrasted with the cultural identity of children living abroad. Our findings also suggest that one form of identity does not necessarily come at the expense of another (Nandi \& Platt, 2015). Indeed, the plurality of cultural identity suggests that migrants can maintain multiple identities that are not necessarily oppositional (Verkuyten, 2007). Further research is warranted to determine whether the plurality of cultural identity is most likely to contribute to social harmony.

\section{Acknowledgments}

This work was supported by the Leverhulme Trust (F/00275/Q) and the National Institute of Social Care and Health Research (SCRA/10/02). We would like to thank Dr. Wendy Martin, Dr. Akile Ahmet, Dr. Stefanie Doebler, and Ethnic Focus for the contributions made to the research project. We acknowledge that the article could not be written without the contribution of the many older people from ethnic groups in England and Wales who took the time to respond to our survey.

\section{Declaration of Conflicts of Interest}

The authors declare that no conflicts of interest exist. 


\section{References}

Akaike, H. (1987). Factor analysis and AIC. Psychometrika, 52, 317-332.

Aronsson, P., \& Gradén, L. (2013). Introduction: Performing Nordic heritage: Institutional preservation and population practices. In P. Aronsson \& L. Gradén (Eds.), Performing Nordic heritage: Everyday practices and institutional culture (pp. 9-10). Farnham, Surrey, UK: Ashgate.

Bhui, K., Stansfeld, S., McKenzie, K., Karlsen, S., Nazroo, J., \& Weich, S. (2005). Racial/ethnic discrimination and common mental disorders among workers: Findings from the EMPIRIC study of ethnic minority groups in the United Kingdom. American Journal of Public Health, 95, 496-501.

Bottero, W. (2004). Class identities and the identity of class. Sociology, 38, 985-1003.

Burholt, V. (2004a). The settlement patterns and residential histories of older Gujaratis, Punjabis and Sylhetis in Birmingham, England. Ageing \& Society, 24, 383-410.

Burholt, V. (2004b). Transnationalism, economic transfers and families' ties: Intercontinental contacts of older Gujaratis, Punjabis and Sylhetis in Birmingham with families abroad. Ethnic \& Racial Studies, 27, 800-829.

Burholt, V., Curry, N., Keating, N., \& Eales, J. (2014). Connecting with community: The nature of belonging among rural elders. In C. Hennessy, R. Means, \& V. Burholt (Eds.), Countryside connections: Older people, community and place in rural Britain (pp. 95-124). Bristol, UK: Policy Press.

Burholt, V., \& Dobbs, C. (2010). Care-giving and care-receiving relationships of older South Asians: Functional exchange and emotional closeness. GeroPsych, 23, 215-225.

Burholt, V., \& Dobbs, C. (2014). A support network typology for application in older populations with a preponderance of multigenerational households. Ageing \& Society, 34, 1142-1169.

Burholt, V., Dobbs, C., \& Victor, C. (2015). Transnational family relationships and cultural identity: Older migrants in England and Wales. The Gerontologist, 55, 785.

Burholt, V., Dobbs, C., Victor, C. V., Martin, W., \& Ahmet, A. (2013). Confirming a support network typology for migrants with a high proportion of multigenerational households. The Gerontologist, 53, 571.

Burholt, V., \& Victor, C. (2014, July). Transnational grandparenting by minority ethnic groups living in England and Wales. XVIII International Sociological Association World Congress of Sociology, Yokohama, Japan. Facing an unequal world: Challenges for Sociology. Book of abstracts. International Sociological Association. Retrieved from http://www.isa-sociology.org/congress2014/isa-wcs2014-book-of-abstracts.pdf

Burholt, V., \& Wenger, G. C. (2004). Migration from South Asia to the UK and the maintenance of intergenerational relationships. In M. Silverstein, R. Giarrusso, \& V. L. Bengtson (Eds.), Intergenerational relations across time and place. Springer annual review of gerontology and geriatrics (pp. 153-176). New York: Springer Publishing.

Burholt, V., Wenger, G. C., Biswas, A. A., Dave, P., Mallya, I., Sodhi, N. S., ... Soneja, S. (2003). Families and migration: Older people from South Asia. Department for International Development (DFID) Project ESA315 final report. Bangor, Wales, UK: Centre for Social Policy Research and Development, University of Wales.

Cheryan, S., \& Monin, B. (2005). "Where are you really from?": Asian Americans and identity denial. Journal of Personality and Social Psychology, 89, 717-730.

Christiansen, F. (2013). Ethnic Chinese in the European economy: Risk and the transnational ethnic enclave. In T.C. Beng (Ed.), Routledge handbook of the Chinese diaspora (pp.141-155). Abindgon, Oxfordshire, UK: Routledge.
Cross, W. E., \& Fhagen-Smith, P. (2001). Patterns in African American identity development: A lifespan perspective. In C. L. Wijeyesinghe \& B. W. Jackson III. (Eds.), New perspectives on racial identity development (pp. 243-70). New York: New York University Press.

Fouad, N. A., \& Brown, M. T. (2000). Role of race and social class in development: Implications for counseling psychology. In S.D. Brown \& R. W. Lent (Eds.), Handbook of counseling psychology (3rd ed., (pp. 379-408). Hoboken, NJ: Wiley.

Grant, R. L., \& Bowling, A. (2011). Challenges in comparing the quality of life of older people between ethnic groups, and the implications for national well-being indicators: A secondary analysis of two cross-sectional surveys. Health \& Quality of Life Outcomes, 9, 109

Hair, J. F. Jr., Anderson, R. E., Tatham, R. L., \& Black, W. C. (1995). Multivariate data analysis (3rd ed.). New York: Macmillan.

Hitlin, S., \& Elder, G. H. (2007). Time, self and the curiously abstract concept of agency. Sociological Theory, 25, 70-91.

Hogg, M. A., Terry, D. J., \& White, K. M. (1995). A tale of two theories: A critical comparison of identity with social identity theory. Social Psychology Quarterly, 58, 255-269.

Hunt, S. (2003). Self reports in research with non-English speakers: The challenge of language and culture is yet to be met. British Medical Journal, 327, 352-353.

James, W. (1890/1950). The principles of psychology. New York: Dover.

Johnson, G. E. (2007). Comings and goings: Pearl River Delta identities in an era of change and transformation. In T. C. Beng (Ed.), Chinese transnational networks (pp. 23-48). London and New York: Routledge.

Karlsen, S., \& Nazroo, J.Y. (2013). Influences on forms of national identity and feeling "at home" among Muslim groups in Britain, Germany and Spain. Ethnicities, 13, 689-708.

Khanna, N. (2016). The connection among racial identity, social class and public policy. In K. O. Korgen (Ed.), Race, policy and multiracial America (pp. 67-80). Bristol, UK: Policy Press.

Koller, M., Aaronson, N. K., Blazeby, J., Bottomley, A., Dewolf, L., Fayers, P., ... the EORTC Quality of Life Group. (2007). Translation procedures for standardized quality of life questionnaires: The European Organization for Research and Treatment of Cancer (EORTC) approach. European Journal of Cancer, 43, $1810-1820$.

Mao, J., \& Shen, Y. (2015). Cultural identity change in expatriates: A social network perspective. Human Relations, 68, 1533-1556.

Mead, G. H. (1934). Mind, self and society. Chicago, IL: University of Chicago Press.

Nandi, A., \& Platt, L. (2015). Patterns of minority and majority identification in a multicultural society. Ethnic \& Racial Studies, 38, 2615-2634.

National Health Service Information Centre. (2010). Comparison of Results from Surveys of Carers, 2009-2010. Leeds, UK: National Health Service Information Centre.

Neyestani, M. R., \& McInturff, P. (2006). Cultural and religious identities in an era of information and communications globalization. Communications of the International Information Management Association IIMA, 6, 87-94.

Nylund, K. L. (2007). Deciding on the number of classes in latent class analysis and growth mixture modeling: A Monte Carlo simulation study. Structural Equation Modeling, 14, 535-569.

Office for National Statistics. (2005). The National Statistics socioeconomic classification user manual. Basingstoke, UK: Palgrave Macmillan.

Padilla, A. M., \& Perez, W. (1993). Acculturation, social identity, and social cognition: A new perspective. Hispanic Journal of Behavioral Science, 25, 35-55.

Phinney, J. S., \& Ong, A. D. (2007). Conceptualization and measurement of ethnic identity: Current status and future directions. Journal of Counseling Psychology, 54, 271-281. 
Portes, A., Guarnizo, L., \& Landolt, P. (1999). The study of transnational communities: Pitfalls and promise of an emergent field. Ethnic \& Racial Studies, 22, 217-237.

Qian, Z. (2004). Options: Racial/ethnic identification of children of intermarried couples. Social Science Quarterly, 85, 746-766.

Roccas, S., \& Brewer, M. B. (2002). Social identity complexity. Personality \& Social Psychology Review, 6, 88-106.

Rose, D., \& Pevalin, D. J., with O'Reilly, K. (2005). The national statistics socioeconomic classification: origins, development and use. Basingstoke, UK: Palgrave MacMillan.

Royal Mail. (2009). Technical specifications for users of PAF® and associated raw data products: Programmers' guide. Edition 7 , version 5.0. Portsmouth, UK: Royal Mail Group.

Savage, M. (2000). Class analysis and social transformation. Oxford, UK: Oxford University Press.

Sclove, L. (1987). Application of model-selection criteria to some problems in multivariate analysis. Psychometrika, 52, 333-343.

Siew-Peng, L. (2001). Satellite television and Chinese migrants in Britain. In R. King \& N. Wood (Eds.), Media and migration: Constructions of mobility and difference (pp. 143-157). London: Routledge.

Silverstein, M., \& Giarrusso, R. (2010). Aging and family life: A decade review. Journal of Marriage \& Family, 72, 1039-1058.

Stets, J. E., \& Burke, P. J. (2000). Identity theory and social identity theory. Social Psychology Quarterly, 63, 224-237.

Tajfel, H. (1981). Human groups and social categories. Cambridge, UK: Cambridge University Press.

Tajfel, H., \& Turner, J.C. (1986). The social identity theory of intergroup behavior. In S. Worchel \& W. G. Austin (Eds.), Psychology of intergroup relations (pp. 7-24). Chicago, IL: Nelson-Hall.

Turner, J. C., Hogg, M. A., Oakes, P. J., Reicher, S. D., \& Wetherell, M.S. (Eds.). (1987). Rediscovering the social group: A self-categorization theory. Oxford, UK: Basil Blackwell.

UNESCO. (2003). Convention for the safeguarding of the intangible cultural heritage. Retrieved from http://www.unesco.org/culture/ich/en/convention

van Oudenhoven, J. P., Ward, C., \& Masgoret, A-M. (2006). Patterns of relations between immigrants and host societies. International Journal of Intercultural Relations, 30, 648-651.

Verkuyten, M. (2007). Religious group identification and interreligious relations: A study among Turkish-Dutch Muslims. Group Processes \& Intergroup Relations, 10, 341-357.

Vertovec, S. (1999). Conceiving and researching transnationalism. Ethnic \& Racial Studies, 22, 447-462.

Vuong, Q. (1989). Likelihood ratio tests for model selection and nonnested hypotheses. Econometrica, 57, 307-333.

Wenger, G. C., \& Burholt, V. (2001). Differences over time in older people's relationships with children, grandchildren, nieces and nephews in rural North Wales. Ageing \& Society, 21, 567-590.

White, L. (2001). Sibling relationships over the life course: A panel analysis. Journal of Marriage \& Family, 63, 555-568.

Xie, Y., \& Goyette, K. (1997). The racial identification of biracial children with one Asian parent: Evidence from the 1990 Census. Social Forces, 76, 547-570.

Manuscript received: 15.11.2015

Manuscript accepted after revision: 10.03.2016

\section{Vanessa Burholt}

Room 20 Haldane Building

Centre for Innovative Ageing

College of Human and Health Science

Swansea University

Singleton Park

Swansea

Wales, UK, SA2 8PP

v.burholt@swansea.ac.uk 